\title{
PENINGKATAN KOMPETENSI GURU MELALUI SUPERVISI AKADEMIK BIRO III PENDIDIKAN DASAR DAN MENENGAH DI SMA NAZHATUT THULLAB
}

\author{
Muhammad Sholeh Hoddin \\ Guru di SMA Nazhatut Thullab, Email: saladin.19800918@gmail.com
}

\begin{abstract}
Abstrak:
Biro III Bag. Dikdasmen adalah salah satu bagian yang secara struktural berada di bawah Ketua Yayasan Pondok Pesantren Nazhatut Thullab yang diberi wewenang sebagai pengembang dan evaluator pendidikan. Penelitian ini bertujuan untuk mengetahui bagaimana kegiatan supervisi dalam meningkatkan kualitas guru, yang dilaksanakan oleh tim supervisor yang dibentuk oleh Biro III Bag. Dikdasmen. Pendekatan yang digunakan dalam penelitian ini adalah deskriptif-kualitatif dengan bentuk studi kasus. Reduksi data (data reduction), penyajian data (data disply), dan verifikasi (verification) merupakan teknik analisa data yang digunakan dalam penelitian ini. Hasil dari penelitian ini adalah bahwa dalam kegaiatan supervisi akademik diawali dengan menyusun perencaan yang meliputi: tujuan, sasaran, penyusunan format instrumen dan waktu pelaksanaan supervisi akademik. Sedangkan dalam tahap pelaksanaannya, dalam supervisi akademik ini, Biro III Bag. Dikdasmen menggunakan teknik observasi kelas dan pembicaran individual yang bersifat sharing, artinya posisi supervisor bukan semata-semata sebagai atasan melainkan sebagai relasi. Evaluasi sebagai tahap akhir dari proses supervisi akademik, mengahasilkan penilaian dan tindaklanjut, yaitu berupa pembinaan, workshop dan promosi kenaikan status kepegawaian.
\end{abstract}

Kata Kunci: Kompetensi guru, supervisi akademik

Abstract: Biro III Bag. Dikdasmen is one part that is structurally under the Chair of the Nazhatut Thullab Boarding School Foundation which is authorized as an education developer and evaluator. This study aims to find out how supervision activities in improving the quality of teachers, carried out by the supervisory team formed by the Biro III Bag. Dikdasmen. The approach used in this study is descriptive-qualitative with the form of case studies. Data reduction, data disply, and verificationare data analysis techniques used in this study. The results of this study are that in academic supervision activities begin with preparing planning which includes: goals, objectives, preparation of the instrument format and the time for conducting academic supervision. While in the implementation stage, in this academic supervision, Biro III Bag. Dikdasmen uses class observation techniques and individual conversations which are sharing, meaning supervisor positions are not merely as superiors but as relationships. Evaluation is the final stage of the academic supervision process, resulting in assessments and follow-up, namely in the form of coaching, workshops and promotion of increased employment status.

Keywords: Teacher Competence, Academic supervision 


\section{PENDAHULUAN}

Undang-undang Republik Indonesia (UU RI) Nomor 20 Tahun 2003, tentang Sistem Pendidikan Nasional (SISDIKNAS), menyatakan bahwa tujuan pendidikan nasional adalah untuk mengembangkan potensi peserta didik agar menjadi manusia yang beriman dan bertakwa kepada Tuhan Yang Maha Esa, berakhlak mulia, sehat, berilmu, cakap, kreatif, mandiri, dan menjadi warga negara yang demokratis serta bertanggungjawab.

Dalam upaya untuk mencapai tujuan di atas dibutuhkan guru yang efektif; yaitu seorang guru yang dapat menunaikan tugas dan fungsinya secara profesional. Untuk melaksanakan tugas secara profesional diperlukan berbagai persyaratan seperti: kompetensi akademik, kompetensi metodologi, kematangan pribadi, sikap penuh dedikasi, kesejahteraan yang memadai, pengembangan karir, budaya kerja dan suasana kerja yang kondusif. ${ }^{1}$

Dalam sistem pendidikan, guru adalah komponen yang sangat menentukan tujuan dan keberhasilan peserta didik, utamanya dalam pembelajaran, sehingga ia perlu mendapatkan prioritas perhatian dan sebagai salah satu subjek pendidikan, guru mempunyai peran yang strategis dalam melakukan transpormasi intelektual serta upaya mengoptimalkan perkembangan potensi, kecakapan dan karekteristik peserta didik. Untuk itu, guru selalu dituntut untuk mengembangkan potensi dan kompetensi diri, baik dari aspek pedagogik, profesional, keperibadian ataupun sosial.

Upaya pengembangan diri tersebut bisa diusahakan oleh dirinya sendiri ataupun orang lain yang bisa membantunya untuk mencapai tujuan tersebut, di antaranya adalah dalam bentuk supervisi yang dilakukan oleh kepala sekolah, pengawas atau lembaga tertentu.

Supervisi sebagai salah satu upaya untuk meningkatkan profesionalitas pendidik, seyogyanya dilaksanakan secara maksimal yang bersifat manusiawi; artinya mengadung unsur pembinaan, bukan mencari-cari kesalahan dan bertujuan agar guru yang disupervisi dapat mengetahui kekurangannya (bukan semata-mata kesalahannya) kemudian untuk dapat diberitahu bagian yang perlu diperbaiki. ${ }^{2}$

Dari hasil supervisi diharapkan seorang guru dapat mengevaluasi diri untuk menjadi lebih professional, sehingga berdampak pada proses dan hasil pendidikan yang berkualitas dalam rangka mewujudkan manusia Indonesia yang tertuang dalam tujuan pendidikan nasional.

Berkaitan dengan kegiatan supervisi, Yayasan Pondok Pesantren Nazhatut Thullab sebagai lembaga pendidikan yang membawahi beberapa unit pendidikan formal, baik tingkat SLTP (MTs dan SMP), SLTA (MA, SMA dan SMK), dan Perguruan Tinggi (STAI dan AKPER), membentuk Biro III sebagai lembaga pengembang dan evaluator pendidikan, yang salah satu tugas dan wewenangnya adalah melaksanakan kegiatan supervisi pendidikan. Dari itu, kegiatan supervisi yang tadinya merupakan tanggungjawab kepala sekolah menjadi tanggungjawab bersama, baik pihak kepala sekolah maupun Biro III.

\footnotetext{
${ }^{1}$ Tobroni, Pendidikan Islam: Paradigma, Filosofis dan Spritualitas (Malang: UMM Press, 2008), 114.

2 Suharsimi Arikunto, Dasar-dasar Supervisi (Jakarta: Rineka Cipta, 2006), 2-3.
} 
Adapun dalam penelitian ini, penulis hanya membatasi peran Biro III sebagai supervisor pada Lembaga Pendidikan Dasar dan Menengah, khususnya di SMA Nazhatut Thullab Prajjan Camplong Sampang.

\section{Supervisi Akademik}

Secara etimologis, supervisi menurut S. Wajowasito dan W.J.S Poerwadarminta yang dikutip oleh Ametembun: "Supervisi dialih bahasakan dari perkataan Inggris "Supervision" artinya pengawasan menyebutkan bahwa dilihat dari bentuk perkataannya, supervisi terdiri dari dua buah kata super + vision: Super = atas, lebih, Vision = lihat, tilik, awasi. ${ }^{3}$ Makna yang terkandung dari pengertian tersebut, bahwa seorang supervisor mempunyai kedudukan atau posisi lebih dari orang yang disupervisi, tugasnya adalah melihat, menilik atau mengawasi orang-orang yang disupervisi.

Secara termenologi, dalam Dictionory of Ecucation Good Carter, yang dikutip oleh Piet A. Sahertian, supervisi adalah upaya yang dilakukkan oleh petugas sekolah dalam memimpin segenap guru dan petugas lainnya dalam memperbaiki pengajaran, termasuk memberi stimulus, menyeleksi jabatan, dan perkembangan guru serta merevisi tujuan pendidikan, bahan pengajaran, dan metode, serta evaluasi pengajaran. ${ }^{4}$

Dalam Q.S. Ali Imran: 29 memberi isyarat mengenai supervisi, berikut ini:

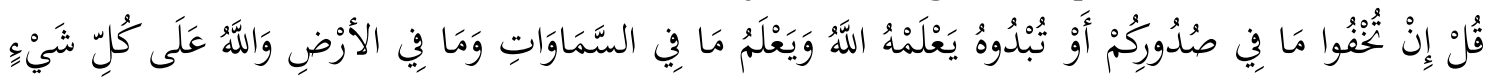

Artinya: Katakanlah: "Jika kamu menyembunyikan apa yang ada dalam hatimu atau kamu melahirkannya, pasti Allah mengetahui." Allah mengetahui apa-apa yang ada di langit dan apa-apa yang ada di bumi. Dan Allah Maha Kuasa atas segala sesuatu" (Depag. RI, tt: 80).

Ayat di atas secara implisit mengungkapkan tentang luasnya cakupan pengetahuan Allah SWT tentang segala sesuatu yang berkaitan dengan mahluk ciptaanya. Demikian pula dalam ayat tersebut mengisyaratkan posisi Allah SWT sebagai Pencipta merupakan pemilik otoritas tertinggi yang membawahi semua mahluk ciptaan-Nya, yang bila dikaitkan dengan konteks beberapa definisi di atas, yaitu supervisi dilakukan oleh atasan atau pimpinan yang tentunya memiliki otoritas yang lebih tinggi terhadap hal-hal yang ada di bawahnya atau bawahannya memiliki kesamaan konsep tentang subjek pelaku supervisi yaitu sama-sama dilakukan oleh subjek yang memilki otoritas yang lebih tinggi terhadap subjek yang lebih rendah/bawahan. ${ }^{5}$

Pelaksanaan supervisi pada satuan pendidikan berdasarkan pada Peraturan Menteri Pendidikan Nasional Nomor 19 Tahun 2007 tentang Standar Pengelolaan Pendidikan oleh Satuan Pendidikan Dasar dan Menengah, menegaskan bahwa sepervisi

\footnotetext{
${ }^{3}$ Ametembun, Supervisi Pendidikan Penuntun Bagi Pembina Pendidik Kepala Sekolah dan Guru-guru (Bandung: Karya Remaja, 1993),2

4 Sahertian, Piet A., Konsep dasar dan Teknik Supervisi Pendidikan, dalam Rangka Pengembangan Sumber Daya Manusia. (Jakarta: PT. Asdi Mahasatya, 2008),17

5 (http://wahyono-saputro.blogspot.com/2013/07/ isyarat-supervisi-dalam-al-quran.html).
} 
pengeloaan akademik dialkukan secara teratur dan berkelanjutan oleh kepala sekolah dan pengawas sekolah.

Selain itu, dalam Permendikanas Nomor 41 Tahun 2007 tentang Standar Pengelolaan Pendidikan oleh Satuan Pendidikan Dasar dan Menengah, juga menegaskan tentang supervise yang berbunyi:

1. Supervisi proses pembelajaran dilakukan pada tahap perencanaan, pelaksanaan, dan penelaian hasil pembelajaran.

2. Supervisi pembelajaran diselenggarakan dengan cara pemberian contoh, diskusi, pelatihan, dan konsultasi.

3. Kegiatan supervise dilakukan oleh kepala dan pengawas sekolah.

Supervisi adalah pengawasan profesional dalam bidang akademik dijalankan berdasarkan kaidah-kaidah keilmuan tentang bidang kerjanya, memahami tentang Akademik lebih mendalam dari sekadar pengawas biasa. ${ }^{6}$ Istilah supervisi atau pengawasan dalam kelembagaan pendidikan diidentikkan dengan supervisi pengawasan profesional, hal ini tentu dihadapkan pada berbagai peristiwa dan kegiatan, contoh jika pengawasan dilakukan oleh kepala sekolah, maka pengawasan dilakukan untuk melihat kinerja guru dalam melaksanakan Akademik terhadap siswa, namun jika supervisi dilaksanakan oleh pengawas satuan pendidikan, maka kepala sekolah dalam konteks kelembagaan jelas menjadi tujuan utama dalam meningkatkan mutu pendidikan secara menyeluruh. ${ }^{7}$

Selanjutnya yang dimaksud dengan supervisi akademik dalam buku Panduan Supervisi Akademik yang diterbitkan oleh Direkorat Pembinaan Sekolah Menegah Atas (2017: 3) adalah serangkaian kegiatan yang bertujuan membantu guru untuk mengembangkan kompetensinya dalam mengelola proses pembelajaran untuk mencapai tujuan pembelajaran. Dari itu, esensi supervisi akademik bukanlah untuk menilai unjuk kerja guru dalam mengelola proses pembelajaran, melainkan membantu guru dalam mengembangkan kompetensi profesionalismenya (Jamal, 2012: 93).

Sedangkan menurut Imron, supervisi akademik adalah serangkaian bantuan yang berupa layanan professional yang diberikan oleh seorang yang lebih ahli kepada kepada seorang guru untuk dapat meningkatkan proses dan hasil belajar, sehingga tujuan pendidikan yang dicanangkan tercapai. 8

Dalam melaksanakan supervisi akademik, yang perlu diperhatikan oleh seorang supervisor adalah ruang lingkup pelaksanaan supervisi akademik yang meliputi beberapa hal, yaitu: ${ }^{9}$

1. Terlaksananya Kurikulum Tingkat Satuan Pendidikan (KTSP)

2. Adanya kesiapan guru dalam persiapan, pelaksanaan dan penilaian pembelajaran

3. Pencapaian standar kelulusan, standar proses, standar isi, dan peraturab pelaksanaannya, serta

4. Peningkatan mutu pembelajaran. Upaya peningkatan mutu pembelajaran dapat dilakukan melalui pengembangan sebagai berikut:

a. Model pembelajaran yang mengacu pada standr proses

\footnotetext{
${ }^{6}$ Moh. Rifa'i. M, Administrasi dan Supervisi Pendidikan (Bandung: Jemmars, 1992), 20.

${ }^{7}$ Oteng Sutisna, Supervisi dan Administrasi Pendidikan (Jakarta: Jemmars, 1983), 237.

${ }^{8}$ Ali Imron, Supervisi Pembelajaran Tingkat Satuan Pendidikan (Jakarta: Bumi Aksara, 2011), 8.

9 Ibid., 99-101.
} 
b. Peran serta peserta didik dalam proses pembelajaran secara aktif, kreatif, demokratis, mendidik, memotivasi, mendorong kreativitas, dan dialogis.

c. Membentuk karakter dan pola pikir, serta memberikan kebebasan berpikir kepada peserta didik.

d. Menempatkan peserta didik sebagai subjek pendidikan dalam proses pembelajaran, sehingga dapat berperan aktif, bersungguh-sungguh dan mendalam untuk mencapai pemahaman konsep, tidak terbatas pada materi.

e. Bertanggungjawab terhadap mutu pembelajaran, agar peserta didik memiliki sejumlah kemampuan, di antaranya:

1) Meningkatkan rasa ingin tahu

2) Mencapai keberhasilan belajar secara konsisten sesuai dengan tujuan pendidikan

3) Memahami perkembangan pengetahuan dengan kemampuan mencari sumber informasi.

4) Mengolah informasi menjadi pengetahuan.

5) Menggunakan pengetahuan untuk menyelesaikan masalah.

6) Mengkomunikasikan pengetahuan dengan pihak lain.

7) Mengembangkan belajar sendiri dan kelompok dengan proporsi yang wajar.

\section{Tahapan Supervisi Akademik}

Dalam Permendikbud Nomor 22 Tahun 2016 tentang Standar Proses dijelaskan bahwa dalam kegiatan supervisi akademik melalui tahapan/siklus yang meliputi, pemantauan, supervisi, pelaporan, daan tindak lanjut.

1. Pemantauan

Pemantauan proses pembelajaran dilakukan pada tahap perencanaan, pelaksanaan, dan penilaian hasil pembelajaran. Pemantauan dapat dilaksanakan dengan cara diskusi kelompok terfokus, pengamatan, pencatatan, perekaman, wawancara, dan dokumentasi.

2. Supervisi

Supervisi proses pembelajaran dilaksanakan, dimulai dari tahap perencanaan, pelaksanaan, dan penilaian hasil pembelajaran yang dilaksanakan melalui, antara lain, pemberian contoh, diskusi, konsultasi, atau pelatihan pelaporan.

3. Hasil kegiatan pemantauan, supervise, dan evaluasi proses pembelajaran disusun dalam bentuk laporan untuk kepentingan tindaklanjut pengembangan keprofesionalan pendidik secara berkelanjutan.

4. Tindak lanjut

Tindak lanjut hasil pengawasan dilakukan dalam bentuk:

a. Penguatan dan penghargaan kepada guru yang menunjukkan kinerja yang memenuhi atau melampaui standar; dan

b. Pemberian kesempatan kepada guru untuk mengikuti program pengembangan keprofesionalan berkelanjutan. 


\section{Teknik Supervisi Akademik}

Ada dua macam teknik yang digunakan dalam kegiatan supervise akademik, yaitu teknik supervisi individual dan teknik supervisi kelompok: ${ }^{10}$

1. Teknik Supervisi Individual

Teknik seupervisi individual adalah pelaksanaan supervisi perseorangan terhadap guru. Dalam teknik supervisi ini terdapat lima macam teknik, yaitu kunjungan kelas, observasi kelas, pertemuan individual, pertemuan antar kelas, dan menilai diri sendiri 2. Teknik Supervisi Kelompok

Teknik supervisi kelompok adalah satu cara melaksanakan program supervisi yang ditunjukkan pada dua orang atau lebih. Guru-guru yang diduga sesuai dengan analisis kebutuhan, memiliki masalah ayau kebutuhan atau kelemahan-kelemahan yang sama dikelompokkan atau dikumpulkan menjadi satu, kemuidan diberi layanan supervise sesuai denga permasalahan atau kebutuhannya.

\section{Metode Penelitian}

Pendekatan yang digunakan dalam penelitian ini adalah deskriptif-kualitatif dengan bentuk studi kasus. Posisi peneliti dalam penelitian ini sebagai instrumen utama (key instrument), sehingga kehadirannya di samping sebagai instrumen juga menjadi faktor penting dalam seluruh kegiatan penelitian. Penelitian yang dilakukan di SMA Nazhatut Thullab yang berada di bawah naungan Yayasan Pondok Pesantren Nazhatut Thullab Prajjan Camplong Sampang, dalam pengumpulan datanya, peneliti menggunakan teknik observasi, wawancara yang mendalam dan dokumentasi. Metode wawancara dalam penelitian, dilakukan terhadap beberapa informan seperti Kepala dan Anggota Biro III Bid. Pendidikan Dasar dan Menengah, Kepala Sekolah, dan Guru. Reduksi data (data reduction), penyajian data (data disply), dan verifikasi (verifikcation) merupakan teknik analisa data yang digunakan dalam penelitian ini. Selanjutnya peneliti melakukan audit hasil penelitian dengan langkah-langkah, berikut: perpanjangan keikutsertaan, ketekunan/keajegan pengamatan, triangulasi, dan pemeriksaan sejawat melalui diskusi.

\section{Profil Biro III Bidang Pendidikan Dasar dan Menengah Pondok Pesantren Nazhatut Thullab}

Biro III bidang Pendidikan adalah satu di antara empat biro yang secara structural berada di bawah Yayasan Pondok Pesantren Nazhatut Thullab yang mempunyai tugas dan fungsi sebagai pengembang dan evaluator Pendidikan, baik Pendidikan dasar dan menengah ataupun Pendidikan tinggi.

Untuk mempermudah kinerja Biro III itu sendiri, maka secara spesifik Biro ini dibagi menjadi dua sub; pertama, Biro III Bidang Pendidikan Dasar dan Menengah; kedua, Biro III Bidang Pendidikan Tinggi.

Adapun yang dimaksud dalam penelitian ini adalah Biro III Bidang Pendidikan Dasar dan Menengah yang meliputi; pertama, pendidikan formal yaitu: MTs. Nazhatut Thullab, SMP. Nazhatut Thullab, SMA Nazhatut Thullab, SMK Nazhatut Thullab, dan MA Nazhatut Thullab; kedua, Pendidikan non formal, yaitu: MADIN Takmiliyah Awwaliyah Nazhatut Thullab, MADIN Takmiliyah Wustho Nazhatut Thullab, dan Taman Pendidikan Al-Qur'an (TPQ) Nazhatut Thullab.

10 Direktorat Pembinaan Sekolah Menengah Atas, Panduan Supervisi Akademik. (Tt: 2017), 10. 
Sebagai lembaga evaluator, maka di antara tugas Biro III Bid. Dikdasmen adalah melakukan supervisi pendidikan terhadap lembaga yang dinaunginya, baik supervisi managerial ataupun Akademik. Dan pada penelitian ini, penulis meneliti kegiatan supervisi Akademik yang dilakukan oleh Biro III Dikdasmen di unit SMA Nazhatut Thullab.

\section{Tahapan Kegiatan Supervisi Akademik SMA Nazhatut Thullab}

Sejalan dengan Undang-undang RI. No 14 Tahun 2003 tentang Guru dan dosen bahwa kegiatan supervisi akademik yang dilaksanakan di SMA Nazhatut Thullab dengan semua pendidik sebagai sasarannya memiliki tujuan untuk meningkatkan kinerja pendidik melalui pengembangan kompetensi pedagogik, profesional, kepribadian dan sosial.

Sebagaimana diketahui di atas, bahwa di antara wewenang Biro III Bid. Dikdasmen adalah melaksanakan kegiatan supervisi di semua unit pendidikan yang berada di bawah naungan Yayasan Pondok Pesantren Nazhatut Thullab, maka dalam kegiatan supervisi akademik ini, kepala sekolah tidak bergerak sendiri tetapi bersama tim supervisi yang dibentuk oleh Biro III Bid. Dikdasmen. Artinya semua tahapan supervisi, mulai dari perencanaan, pelaksanaan, dan evaluasi merupakan keputusan dan dilaksanakan oleh tim.

\section{Perencanaan Kegiatan Supervisi Akademik}

Langkah awal dari kegiatan supervisi akademik ini adalah perencanaan kegiatan yang berupa penyusunan program kerja selama satu tahun yag meliputi; tujuan, sasaran, penyusunan format instrumen dan waktu pelaksanaan supervisi pebelajaran.

1. Tujuan Pelaksanaan Kegiatan Supervisi Akademik

Dalam Sahertian dijelaskan bahwa pelaksanaan supervisi memiliki tujuan untuk memberikan layanan dan bantuan dalam pengembangan dan peningkatan kualitas pendidik dalam situasi belajar-mengajar di dalam kelas. Sedangkan menurut menurut Feter F. Oliva yang dikutip oleh Muslim, menjelaskan bahwa supervise memiliki 3 (tiga) tujuan yaitu; (1) membantu guru dalam mengembangkan proses Akademik, (2) membantu guru dalam menterjemahkandan mengembangkan kurikulum dalam proses Akademik, (3) membantu sekolah dalam mengembangkan staf. ${ }^{11}$

Sebagaiman hal di atas, tujuan dilaksanakaan kegiatan supervisi akademik di SMA Nazhatut Thullab mencakup pada seluruh aspek kompetensi guru, yaitu untuk meningkatkan kinerja pendidik melalui pengembangan kompetensi pedagogik, profesionalisme, kepribadian, dan sosial.

2. Sasaran

Termaktub dalam UURI No. 14 Tahun 2005, tentang Guru dan Dosen, Pasal 20 bahwa sasaran utama dalam supervisi adalah guru dengan tugas utamanya merencanakan pembelajaran, melaksanakan proses pembelajaran bermutu, serta menilai, dan mengevaluasi hasil pembelajaran. Mengacu pada Undang-undang di atas, maka yang menjadi sasaran dalam kegiatan supervisi akademik ini adalah segenap tenaga pendidik yang aktif mengajar di SMA Nazhatut Thullab, sebanyak 32

${ }^{11}$ Sahertian, Konsep Dasar .....,19. 
orang dengan perincian sebagai berikut; Guru PNS yang diperbantukan (DPK) sebanyak 5 (lima) orang atau 16\%, GTY sebanyak 12 (dua belas) orang atau 37\%,, dan GTT sebanyak 15 (lima belas) orang atau 47\%.

3. Penyusunan Format Instrumen Supervisi Pebelajaran

Sebelum kegiatan supervise akademik dilaksanakan, terlebih dahulu tim supervisi mengadakan rapat untuk menentukan dan menyepakati format supervise yang akan digunakan. Selanjutnya agar tidak terjadi kesalahfahaman antara tim supervise dan guru, maka format tersebut disebarkan kepada semua guru yang menjadi sasaran dengan tujuan agar mereka bisa memahami dan mempersiapkan diri lebih awal.

Selain penyusunan format instrument, di dalam rapat juga membahas dan membagi guru yang akan disupervisi, sesuai jumlah supervisor yang bertugas di unit SMA Nazhatut Thullab, yaitu tiga orang.

4. Waktu

Adapun waktu pelaksanaan supervisi Akademik ini adalah selama satu semester dengan minimal 1 (satu) kali kegiatan untuk masing-masing guru.

\section{Pelaksanaan Supervisi Akademik}

Dalam pelaksanaan kegiatan supervisi Akademik, Biro III Bag. Dikdasmen menggunakan teknis observasi kelas. Sebelum melaksankan observasi, terlebih dahulu supervisor dan guru melakukan sharing tentang perangkat pembelajaran yang akan digunakan pada waktu pelaksanaan pembelajaran yang akan disupervisi, biasanya pertemuan ini dilakukan beberapa hari sebelum kegiatan observasi kelas dilaksanakan. Dalam diskusi ini, supervisor menanamkan suasana keakraban dan keterbukaan, agar guru tidak merasa sungkan dan takut serta tidak menganggap bahwa supervise ini hanya bertujuan untuk mencari kesalahan guru. Selain menganalisa perangkat pemebelajaran, dalam diskusi ini, supervisor juga memberikan format instrument observasi kepada guru tersebut dengan tujuan agar terjadi kesefahaman antar keduanya.

Tahap selajutnya yaitu observasi kelas, dengan menggunakan jenis observasi langsung, yaitu dengan menggunakan alat observasi berupa instrument dan berada dalam kelas, sehingga supervisor dapat mengamati secara langsung semua aktiftas guru dan siswa. ${ }^{12}$

Dalam kegiatan ini, guru mengaktualisasikan kemampuannya dalam proses Akademik serta penguasaan manajemen kelas sesuai dengan kesepakatan dalam diskusi sebelumnya. Di pihak lain, supervisor melakukan pengamatan terhadap proses pembelajaran tersebut dengan menggunakan instrument yang sudah disepakati.

Tugas supervisor hanya mengamati dan mencatat hal-hal yang perlu diperbaiki nantinya, sehingga apabila guru melakukan kesalahan, maka supervisor tidak boleh menegor, atau mengingatkan.

Setelah kegiatan observasi selesai, keduanya bertemu kembali untuk membicarakan capaian yang dianggap cukup atau temuan-temuan yang perlu dicarikan solusi untuk perbaikan selanjutnya.

12 Sahertian, Konsep Dasar .....,55 
Pembicaran antara supervisor dan guru yang bersifat sharing ini, dilakukan setelah kegiatan observasi atau ketika guru mempunyai permasalahan dalam proses Akademik. Terbangunnya keakraban antar komponen di lingkungan Yayasan Pondok Pesantren Nahatut Thullab, menyebabkan guru tidak sungkan untuk bertemu dengan para supervisor.

Dari pembahasan di atas dapat disimpulkan bahwa dalam proses supervisi akademik ini, Biro III Bagian Dikdasmen (dalam hal ini adalah supervisor sebagai pelaksana) menggunakan 2 (dua) teknik, yaitu: observasi kelas dan percakapan individual.

\section{Evaluasi Hasil Supervisi}

Tahap akhir dari kegiatan supervisi Akademik adalah evaluasi dari hasil supervisi yang meliputi penilaian dan tindaklanjut yang berupa feedback kepada para pendidik. Penilaian adalah komulasi skor yang diperoleh dari instrumen observasi. Sedangkan tindaklanjut yang dimaksud adalah berupa follow up dari temuan yang diperoleh di lapangan.

Ada tiga tindaklanjut yang dilakukan oleh Biro III Bag. Dikdasmen, melalui tim supervisor, yaitu:

\section{Pembinaan}

Pembinaan yang dilakukan oleh superviser terhadap guru berupa refleksi hasil observasi, sehingga guru bisa mengetahui kelebihan dan kekurangan kegiatan Akademik yang telah dilaksanakan.

2. Workshop Akademik

Pelaksanaan workshop Akademik merupakan salah satu agenda tahunan yang dilaksanakan di awal tahun pembelajaran dengan mendatangkan nara sumber yang berkompeten di bidang pendidikan. Selain untuk me-refresh kembali pemahaman guru terhadap pembelajaran, kegiatan ini juga bertujuan untuk mempersiapkan perangkat Akademik yang akan digunakan pada tahun pelajaran baru.

3. Promosi Kenaikan Status Kepegawaian atau Peningkatan Kesejahtraan

Dalam setiap dua tahun Yayasan Pondok Pesantren Nazhatut Thullab memberikan kesempatan kepada guru untuk mengajukan status kepegawaian dari CGTT ke GTT, GTT ke CGTY, CGTY ke GTY. Untuk mencapai kenaikan status kepegawaian, guru harus mendapatkan hasil komulasi dari penilaian supervisi akademik, kedisiplinan, kepribadian dan sosial. Artinya guru yang akan dipromosikan kenaikan status kepegawaiannya adalah guru yang memenuhi krtiteria baik dari aspek kompetensi pedagogik, profesionalisme, kepribadian, dan sosial. 


\section{Kesimpulan}

Sebagai lembaga pengembang dan evaluator, Biro III Bag. Dikdasmen membentuk tim supervisor dalam melakukan supervisi manajerial dan Akademik. Supervisi akademik yang bertujuan untuk membantu guru secara profesional dalam meningkatkan kualitas proses dan hasil belajar, dilaksanakan melalui tahapantahapan yang telah disepakati dalam rapat, meliputi perencanaan, pelaksanaan dan evaluasi. Selanjutnya supervisi akademik ini diawali dengan menyusun perencaan yang meliputi: tujuan, sasaran, penyusunan format instrumen dan waktu pelaksanaan supervisi akademik.

Sedangkan dalam tahap pelaksanaannya, dalam supervisi akademik ini, Biro III Bag. Dikdasmen menggunakan teknik observasi kelas dan pembicaran individual yang bersifat sharing, artinya posisi supervisor bukan semata-semata sebagai atasan melainkan sebagai relasi. Evaluasi sebagai tahap akhir dari proses supervisi akademik, mengahasilkan penilaian dan tindaklanjut, yaitu berupa pembinaan, workshop dan promosi kenaikan status kepegawaian.

\section{DAFTAR RUJUKAN}

Arikunto, Suharsimi. Prosedur Penelitian Suatu Pendekatan Praktek: Edisi Revisi V. (Jakarta: Rineka Cipta, 2002) , Dasar-dasar Supervisi. (Jakarta: Rineka Cipta, 2006)

Asmani, Jamal Ma'mur. Tips Efektif Supervisi Pendidikan Sekolah. (Yogyakarta: Diva Press, 2012)

Departemen Pendidikan Nasional. Kamus Besar Bahasa Indonesia. (Jakarta: Balai Pustaka, 2005)

Glickman, Supervision of Instruction. (Boston: Allyn And Bacon Inc. 1995)

Hariwung, A.J. Supervisi Pendidikan. (Jakarta: Depdikbud, 1989)

Imron, Ali. Supervisi Pembelajaran Tingkat Satuan Pendidikan. (Jakarta: Bumi Aksara, 2011)

Moleong, Lexy J. Metode Penelitian Kualitatf. (Bandung: PT. Remaja Rosdakarya, 2006)

Muslim, Sri Banun. Supervisi Pendidikan Meningkatkan Kualitas Profesionalisme Guru. (Tt: Alfabeta, 2010)

N.A. Ametembun, Supervisi Pendidikan Penuntun Bagi Pembina Pendidik Kepala Sekolah dan Guru-guru. (Bandung: Karya Remaja, 1993)

Purwanto, Ngalim. Administrasi dan Supervisi Pendidikan, (Bandung: Rosdakarya, 2003)

Rifa'i. M, Moh. Administrasi dan Supervisi Pendidikan. (Bandung: Jemmars, 1992)

Sahertian, Piet A. Konsep dasar dan Teknik Supervisi Pendidikan, dalam Rangka Pengembangan Sumber Daya Manusia. (Jakarta: PT. Asdi Mahasatya, 2008)

Sugiyono. Metode Penelitian Kuantitatif, Kualitatif dan R\&D. (Bandung: Alfabeta, 2008)

Sutisna, Oteng. Supervisi dan Administrasi Pendidikan. (Jakarta: Jemmars, 1979)

The New Oxford Illustrated Dictionary. (Oxford University Press, 1982)

Tobroni, Pendidikan Islam: Paradigma, Filosofis dan Spritualitas. (Malang: UMM Press, 2008) 